\title{
Regional Policy in the EU Mode of Regionalism: Implications for Asian Integration
}

\author{
Bruce Wilson \\ European Union Centre at RMIT \\ bruce.wilson@rmit.edu.au
}

\begin{abstract}
Regional Policy continues to be a central part of the overall framework of the European Union's (EU) approach to developing a supranational political and economic entity. It accounts for more than one third of the EU's expenditure and involves complex challenges of redistributing resources from subnational regions in some nations to poorer regions in other nation states. What can nations in other parts of the world that are engaged in pursuit of greater integration learn from the EU's experience, and to what extent are such understandings relevant to other nations? This paper will review both these questions, with specific attention to the Asian context. It will consider some examples of the interest in subnational regional policy within specific Asian countries, with a view to exploring the potential redistribution from richer to poorer regions in Asia.
\end{abstract}

Key words: Asia, Comparative studies, EU-Asia, European Union, Regional development, Regional policy

\section{Introduction}

Regional Policy continues to be a central part of the overall framework of the European Union's (EU) approach to developing a supranational political and economic entity. It accounts for more than one third of the EU's expenditure and involves complex challenges of focusing and redistributing resources predominantly from certain Member States to poorer regions in other nation states. Increasingly, Regional Policy is directed towards achieving the strategic objectives of Europe 2020.

What can nations in other parts of the world that are engaged in pursuit of greater international integration learn from the EU's experience? The first challenge is to develop an understanding of the underlying intent, and of the implementation of regional policy in achieving its objectives. Secondly, it is necessary to address the question about the extent to which those understandings are relevant to nations in other parts of the world, however they define themselves and their potential supranational integration. 
This paper will review both these questions, paying specific attention to the Asian context, specifically the ASEAN nations. It will consider some examples of interest in subnational regional policy within specific Asian countries, with a view to exploring the potential value of a supranational approach to regions in Asia. Some reference will be made to regional development policy in the Australian context, as a counterpoint to both the European experience and the potential development of regional policy in Asia.

\section{Why Do Regions and Regional Policy Matter?}

Regional Policy might be significant in Europe, but why should it matter in Asia? Why might efforts to address supranational integration in the Asian region consider the issues associated with subnational regional development?

In a recent review of trends over the past decade, the OECD has indicated that a small proportion of regions (around 10 per cent, from many different countries) accounted for 40 per cent of the total OECD growth. 'Local factors matter for national sustained growth'. ${ }^{1}$ Local factors, in turn, drive policy formation as efforts are made to realise unfulfilled opportunities in lower performing regions. ${ }^{2}$

The OECD stimulated debate on the importance of regional policy in naming a report published in 2009 as Regions Matter. The focus of the report was the recognition that the historical distinction between either a top-down national policy, or bottom-up, self-reliant approach to regional development was outmoded. Rather, the economic and social well-being of regions depended on a mix of policies which varied from setting to setting, yet in each instance required attention to the key assets of each region. It examines the importance of policy which enhances infrastructure, human capital development and innovation, taking account of the insights of urban and rural perspectives as appropriate. The complexity of multi-level governance was identified as a key influence on the effectiveness and impact of regional policy programs.

More generally, other researchers have reviewed the wider research on the impact of an increasingly globalised world economy, driven by intensified competition, neo-liberal public policy and facilitated by new information and communications technologies. They drew the overall conclusion that contrary to expectations, local and regional governments have been exposed more strongly to the consequences of these forces than national governments.

Globalisation has also been found to have a stronger impact on subnational government, because that is where the dominant features of globalization, migration, urbanization and global economic competition are most strongly felt... Alongside these significant challenges, globalization also brought a new

${ }^{1}$ OECD (2011) Regions at a Glance 2011, Development Studies Centre, Paris, OECD Publishing, p.3. ${ }^{2}$ OECD (2012) Industrial Policy and Territorial Development: Lessons from Korea, Development Studies Centre, Paris, OECD Publishing. 
set of opportunity structures to cities and regions... a new gateway to international arenas and markets. 3

Pierre discusses the ways in which city and regional governments have moved to establish their own international linkages and partnerships, sometimes quite independently of national policies. Regional economic policies drive many of these connections, either facilitating access to investment or capability, or opening up new markets. Of course, within Europe, regions are recognised in the formal decision-making structures (the Committee for Regions). However, there are many examples of regional authorities setting up their own offices in Brussels to be closer to policy formation, decision-making and alliance-building.

Taken together, this demonstrates that regions, sometimes city-regions, are significant economic and political actors in the global economy. When considering both economic policy interventions and governance processes these regions warrant closer attention.

\section{EU Regional Policy}

Given the priority on regions and regional development, the EU's Regional Policy can be seen to constitute a significant part of the EU 'mode of regionalism'. There are various ways of making sense of EU Regional Policy. In the first place, the EU itself has described its objectives as being: to help each region achieve its full potential to improve competitiveness and employment at the regional level by investing in areas of high growth potential; to bring living standards in the countries that have joined the EU since 2004 up to the EU average as quickly as possible. 4

The key elements of European Regional policy reflect the view that redistribution between richer and poorer regions across the different Member States of Europe has been, and is, needed in order to both support and mitigate the effects of further economic integration. This complements the initiatives taken by individual Member States to address regional issues within their own borders. In keeping with the principle of subsidiarity, the EU can act only in ways which go beyond and add value to the action taken by a particular Member State or a subordinate level of government within its borders.

Since 1988, the Union has invested more than €80o billion in the 'less favoured' regions. The main beneficiaries have been Greece and Portugal, with more recent attention being addressed to the regions in the newer Member States in Eastern Europe. While social purposes are important, regional policy is not a welfare program but a targeted investment to stimulate economic growth and employment

\footnotetext{
3 J. Pierre, 'Why Should We Concern Ourselves with Urban Governance? Revisiting the Global-Local Nexus' in Chin-Peng Chu, Alexander Grosse, Sang-Chui Park, Markus Porsche-Ludwig, (eds.), Local Governance in the Global Context, Berlin, Lit Verlag, 2010, pp. 13-14.

$4<$ http://europa.eu/pol/reg/index_en.htm $>$ ), last accessed 12 June, 2013.
} 
The purposes and parameters of Regional Policy are articulated in European legislation dating back to the 1970s. For the current period, 2007-13, Council Regulation 1083/2006, 11 July 2006, provides general provisions on the European Regional Development Fund (ERDF), the European Social Fund (ESF) and the Cohesion Fund. Its aim is to promote the 'harmonious, balanced and sustainable development' of European regions, assisting them to address 'economic, social and territorial inequalities, the acceleration of economic restructuring and the ageing of the population'.5 The Regulation goes on to define the context, objectives, criteria for eligibility, the financial provisions, and the principles and rules for partnerships. For 2007-2013, three new objectives were set out: to encourage convergence, regional competitiveness and territorial co-operation. With respect to the latter, specific funding has been established to facilitate sharing about the implementation of regional activities.

The Directorate General for Regional and Urban Policy has a key role in implementing the policy:

By co-financing infrastructure projects, developing the information society, accelerating the transfer of know-how, supporting investments in people and stimulating cross-border cooperation, the Directorate General for Regional Policy helps regions that are less prosperous or are suffering from structural problems to improve competitiveness and to achieve a faster rate of economic development in a sustainable way. The policy is thus an important expression of the solidarity of the European Union. ${ }^{6}$

The Directorate General (DG) manages two of the major Funds, the ERDF (easily the largest Fund, heavily concentrated in the regions with lowest GDP/head) and the Cohesion Fund (co-finances transport and environment projects in Member States whose GNP is less than 90\% of the Community average), as well as a fund directed towards candidate countries to develop transport networks and environmental infrastructure. The DG also manages disaster assistance.

For the 2007-2013 period the Cohesion Fund concerns Bulgaria, Cyprus, the Czech Republic, Estonia, Greece, Hungary, Latvia, Lithuania, Malta, Poland, Portugal, Romania, Slovakia and Slovenia. Spain is eligible to a phase-out fund only as its GNI per inhabitant is less than the average of the EU-15. Hence, Regional Policy encompasses a complex interplay amongst initiatives intended to facilitate economic competitiveness in poorer regions, improved social cohesion and stronger recognition of territorial connections across borders. Underpinning all of this is the idea of the Single Market, its expansion and the strengthening of poorer parts of the EU to both produce and to consume successfully as part of the largest marketplace in the world.

$5<$ http://europa.eu/legislation summaries/regional policy/ provisions_and_instruments/g24231_en.htm>, accessed 12 June 2013.

${ }^{6}$ EC, European Commission, Fifth Report on Economic, Social and Territorial Cohesion Brussels, November, 2010. 
In this context, Regional Policy needs to be seen alongside the Schengen Treaty and the Eurozone as a key means of facilitating the conditions for effective European-wide movements of people and goods. Over time, the products and services of poorer regions should be able to compete in the wealthier areas of Europe, the incomes and standard of their populations should improve and their markets ought to offer similar opportunities for consumers as in the wealthier regions. By 2020, when Europe is 'smart, sustainable and inclusive', the current disparities revealed in the Fifth Report on Economic, Social and Territorial Cohesion7 should be reduced greatly.

Currently, the wealthiest regions of the EU are seven times richer than the poorest regions. To achieve the required outcomes of the Europe 2020 strategy the Fifth Report reasons there needs to be close coordination between the Europe 2020 strategy, Regional Policy and other EU policies so that policy initiatives are not implemented in isolation. While the report focuses on innovation it also lists infrastructure as a main driver of recovery. There is wide disparity in transport infrastructure across the regions of the EU. Many of the central and eastern Member States do not have direct access to motorways, air transport and high speed rail, which lowers employment rates and the GDP per capita as companies struggle to bring their goods and services to market at a competitive price. Broadband has assisted many of these Member States to gain access to EU-wide markets and even new global markets. However, the report states that broadband access across the EU, is far from universal: in Romania, by way of example, only 13 per cent of their households have a broadband connection, while in Finland up to 84 per cent of households have a broadband connection. To redress this disparity the report suggests there needs to be a more coordinated approach to the investment in and delivery of infrastructure across the EU and its Member States

Member States are restricted from using finances from Regional Policy to replace existing equivalent expenditure. Only a small amount of spending on education is eligible for funding from the Cohesion Fund. However, the Cohesion Fund does support the training of around 10 million low skilled, long term unemployed and young people each year through various local development initiatives.

A major initiative of the Cohesion Fund is to enhance environmental sustainability across the EU and its Member States. The Europe 2020 strategy has a target to achieve 20\% of its energy consumption from renewable sources. To achieve this target there will need to be significant investment in solar and wind energy in southern Europe, the North Sea coast and along the Atlantic. The EU has set a target of reducing its greenhouse gas emissions by 20 per cent and will require investment by both private and public sectors. More funding at local and regional levels is required also to facilitate progress in treating waste water in particular in the southern and eastern Member States.

7 EC, European Commission, Fifth Report on Economic, Social and Territorial Cohesion Brussels, November 2010. 


\section{The Politics of EU Regional Policy Making}

The first insight is that far from being an altruistic program of transfers from the larger and wealthier countries to the poorer, regional policy has been driven by a complex mix of economic, social and political motives. While the economic and social dimensions of the policy have been crucial aspects of the outcomes delivered for particular regions, they have also played a key role as an incentive for greater economic integration in the EU more broadly. ${ }^{8}$ In this respect, it remains very much a program implemented on behalf of, rather than for specific regions. Member State agencies play a key role in the management of regional development resources within their boundaries.

Over the past 20 years these complexities have prompted a considerable body of research on the development and implementation of the policy by the EU. Some of this work has focused on the EU politics themselves, as well as the management and disbursement of the Funds and their impact, while comprehensive literature on the underlying or related theories of regional development and innovation has emerged. There has been a consistent flow of research on the evaluation processes used to monitor the achievements of Regional Policy. 9

The continuing redefinition of the role of Member States can be seen in the evolution of the EU model with respect to the determination of regions for policy implementation purposes. Far from being self-evident, this issue is highly contested. In the first decade or so, Member States retained control over the designation of EU regional policy areas. However, in 1988, the European Commission achieved Council support for the determination of regional boundaries at EU level, with consequences for which regions became eligible for one category of support or not.

The 1988 structural funds regulation (OJEC No. L185 of 15 July 1988) changed this situation dramatically with the introduction of an EU-wide typology of regions (objectives 1, 2 and 5b) using EU criteria and indicators. Objective 1 areas were determined by top-down criteria (EU averages of GDP per head) and the Commission oversaw, and intervened in, the selection of objective 2 and $5 \mathrm{~b}$ areas. ${ }^{10}$

For the subsequent decade, there continued to be intense struggle over these processes. In the 2000-06 negotiations, the European Commission exercised

\footnotetext{
${ }^{8}$ L. Hooghe, L. and M. Keating, 'The politics of European Union regional policy' Journal of European Public Policy Vol. 1 No. 3. 1994

9 See, in turn, J. Wozniak-Boyle, Conditional Leadership: The European Commission and European Regional Policy, Lexington Books, Oxford UK, 2006, C. Mendez, 'The post-2013 reform of EU cohesion policy and the place-based narrative' Journal of European Public Policy Vol. 20 No. 5, 2013;F. Moulaert. and F.Sekia, 'Territorial Innovation Models: A Critical Survey', Regional Studies, Vol. 37 No. 3, 2003 ; R. Rutten and F. Boekema, 'From Learning Region to Learning in a Socio-spatial Context' Regional Studies Vol. 46 No. 8, 2012; C. Mendez and J. Bachtler, "Administrative Reform and Unintended Consequences: An Assessment of the EU Cohesion Policy 'Audit Explosion'” Journal of European Public Policy, Vol. 18 No. 5, 2011.

10 C. Mendez, F. Wishlade, F. and D. Yuill, 'Conditioning and Fine-Tuning Europeanization: Negotiating Regional Policy Maps under the EU's Competition and Cohesion Policies' JCMS, Vol.44 No. 3, 2006 p. 588 .
} 
considerable pressure to limit the scope of regions benefiting from regional funds so as to enhance their impact. Progress was made with this objective, partly because negotiations ensured that the transition would be measured and would therefore not risk unintended impact on regions from which funds were withdrawn. This process was complicated by parallel negotiations over the implementation of competition policy, and the areas to which Member States could offer regional aid. At the insistence of DG Regions, there was a close correspondence in the designated areas for both initiatives.

In this context, there is scarcely an aspect of Regional Policy which has not been subject to critical review, from independent researchers and from key stakeholders in the various institutions of the European Union itself. Successive processes within the Commission (such as the Barca Report in 200911) have continually recognised these critiques and attempted to redefine the policy framework in a manner that clarified its rationale, and improved its implementation. More recently, there has been active collaboration with the OECD in the effort to understand the dynamics of institutional investment in regional development, and how this might be accomplished most effectively. ${ }^{12}$

The overall effectiveness and impact of regional development has itself been contested. It is inherently difficult to assess, , partly because of the various implications for economic growth, social cohesion and equity. Alongside these specific questions, debate about the alternative uses to which the structural funds could have been deployed complicates matters. While positive outcomes have been identified, there continue to be pressure to improve the focus and delivery of the structural funds. 13

2013 marks the conclusion of the current EU budget period and hence of the current iteration of Regional Policy. Intense debate is underway over how it should be structured for the 2014-2020 period. The overall strategy, Europe 2020, sets a clear context for these discussions. The two broad issues are the extent to which EU policy does complement national initiatives appropriately, and whether Regional Policy ought to be more closely entwined with other related policy areas. Draft legislation proposed by the European Commission suggests that, while total funding will increase slightly, there should be fewer investment priorities that are 'harmonised' with initiatives in rural development and maritime and fisheries.

In relation to the first of these, it is apparent that some national investments might have quite unintended consequences for regional policy. Polverari and Michie draw attention to possible overlap and contradiction between regional policy, and national policies related to capital expenditure, labour market, welfare and social protection, rural and transport. They note, however, that there tends to be a high level of 'fit' between the EU programs and national

\footnotetext{
${ }^{11} \mathrm{~F}$. Barca, 'An agenda for a reformed cohesion policy: a place-based approach to meeting European Union challenges and expectations' Independent Report prepared at the request of Danura Hübner, Commissioner for Regional Policy, DG Regional Policy, Brussels, 2009.

${ }^{12}$ See the OECD Working Party on Innovation and Technology Policy (2013) Synthesis Report on Innovation-Driven Growth in Regions: The Role of Smart Specialisation Paris.

13 J. Tugores, Regional integration and public policy: Evaluation of the European experience and possible implications for Latin America integration estudios y perspectivas, Sede Subregional de la Cepal (UN), Mexico, July 2008.
} 
spatially-oriented programs, not least because the EU priorities and funding shape national priorities. There is extensive evidence that national bodies make both strategic and institutional arrangements to coordinate their commitment with that of the EU. They also confirm tensions, identified by others, that relate to the administrative burden and the over-emphasis on financial accountability. ${ }^{14}$

Another challenge for the next iteration of Regional Policy is the priority that will be placed on cross-border initiatives. Already, regional policy initiatives are presented as key levers for the implementation of the wider 'smart, inclusive and sustainable' strategy. It seems likely that projects which enhance cross-border activity will gain stronger support.

\section{Regional Development Policy in Australia}

In Australia, regional development policy has a much less prominent and consistent standing. Research on regional development issues has been uneven and there is little to show that policy development has been evidencebased. To some degree, this can be explained by Australia's federal structure and the prominence of the Federal Government in economic policy and management, while state (and local) governments have been preoccupied with spatial planning and service delivery.

However, the increasingly apparent discrepancy in in the economic and social circumstances of regions in different parts of the country has led to the description of Australia as a 'patchwork' economy. This has drawn attention to the need for local and state governments to advocate for, and themselves contribute to, greater sensitivity in economic and industry policy, taking account of the diverse circumstances of different regions.

Apart from the challenge of identifying appropriate policy interventions, Australian regional development has been undermined significantly by inadequate governance. Lack of clarity in the roles and capacity of federal, state and local governments has led to various mechanisms being created to overcome fractured identity and incoherent coordination. The most recent of these, Regional Development Australia committees, has been structured to bring together a tripartite and community perspective on the needs of communities, and to collate applications for major funding investment in their regions. Their effectiveness has depended on the extent to which they have been able to establish clarity in role, confidence in the rationality of decisionmaking, and legitimacy with local stakeholders. ${ }^{15}$

\section{Examples of Asian Regional Development Policy}

Asian countries differ widely, and typically pay little explicit attention to regional development issues. There is scant evidence of a systematic debate or

\footnotetext{
${ }^{14}$ L. Polverari and R. Michie, Complementarity or Conflict: the (in)coherence of Cohesion policy European Policy Research Paper, No. 78 Glasgow, European Policies Research Centre, Strathclyde University, 2011.

${ }^{15}$ See Regional Australia Institute, The Priorities and Research of Non-Metropolitan Regional Development Australia Committees Canberra, May 2012.
} 
analysis of regional development policies within Asian nations, let alone of the place that such policies might have in the wider processes of economic growth, equity or social cohesion throughout the Asian region. Yeung ${ }^{16}$ has provided an analytic overview of Asian regional development trajectories and how they are linked with global production networks, but this did not address the kinds of wider objectives which characterise EU Regional Policy.

However, a number of Asian countries have clearly recognised their internal regional variations and have adopted policy interventions which might address at least questions of uneven development, and possibly a range of other cultural, economic, social and political issues. These commitments stop well short of the regional policy interventions which the EU sponsors within Member States, not least the transfer of resources from regions with greater to lesser production outputs and lower standards of living.

As in Europe, there has been some diversity in the regional development approaches in Asian countries. In Malaysia for example, reducing regional disparities has been a key objective of recent Seventh and Eighth Plans. While all parts of the country have recorded growth and an improved aggregate standard of living, the disparities amongst states and between the cities and rural areas have widened. Despite difficulties in obtaining adequate data to measure disparity, the Future Plan will again seek to reduce development gaps as measured by per capita and household income, across the states in the Peninsular, Sabah and Sarawak. ${ }^{17}$ The Malaysian Government has provided specific impetus to regional innovation systems through its support for the Multimedia Super Corridor. While it has attracted some large international firms, it has not yet succeeded in stimulating strong clusters of small and medium-sized enterprises. ${ }^{18}$

In Korea, the adoption of a stronger subnational regional policy over the past decade or so was a reaction to the earlier strategy of 'growth first and distribution later... the rapid industrialization has created spatial polarization between Seoul, the southeastern coast... and other areas'.19 These disparities were reinforced by the implementation of free trade zones in Busan and Masan. Distinctions arising from economic inequality were reinforced by very strong patterns of regional antipathy which have persisted for hundreds of years. National government initiatives to engage more with more balanced development across regions have been accompanied by a growing importance of local citizen democracy, which has had a positive impact on public policy. ${ }^{20}$

The OECD has ascribed the growth of regional policy in Korea to three key drivers:

\footnotetext{
${ }^{16}$ H. W. Yeung, 'Regional Development and the Competitive Dynamics of Global Production Networks: An East Asian Perspective' Regional Studies, Vol. 43 No. 3, 2009..

17 M.S. Krimi, Z. Yusop, Z. and L.S.Hook, 'Regional Disparities in Malaysia' Journal of American Science Vol. 6, No. 3, 2010.

${ }^{18}$ UN ESCAP, United Nations Economic and Social Commission for Asia Pacific (2006) Enhancing the Competitiveness of SMEs: Subnational Innovation Systems and Technological Capacity-Building Policies Bangkok.

${ }^{19}$ S-C Park, 'Local Governance in Korea from the Perspective of Regionalism' in C-p. Chu et. al, (eds.) Local Governance in the Global Context Berlin, Lit Verlag, 2010, p. 224. 20 Ibid.
} 
the process of democratisation which gave more power and responsibilities to sub-national governments;

the attention given to local and regional innovation systems in the wake of the Asian crisis in 1997; and

the emerging priority of the knowledge economy, which prompted interest in local and regional production dynamics. ${ }^{21}$

They indicate that the policy intent initially was to improve the efficiency of industrial policy. While Korea's strength was its capacity to co-ordinate human capital planning and industrial development through cluster-based industrial complexes, some regions did not have the capability to take advantage of the new opportunities, even where regional development initiatives were encouraging cluster development in regions. Over time, the policy evolved to 'dig deeper into untapped sources of growth and mobilise growth and innovation potential in all regions of the country by stimulating bottom-up initiatives and networks'.22 As economic growth gathered momentum, the centrally-driven emphasis on particular sectors and technology, with an explicit 'catch-up' understanding of the implications for peripheral regions, was supplemented by a more targeted emphasis on dispersed regional initiatives. However, this was not easy to manage; early patterns of development did not necessarily 'spill over' to other regions.

Experience shows that taking into account the territory consists of much more than "planning actions" in a given "space". The territory comes with endowments - history, memory and capabilities - that are context-specific and that could increase the impact of policy actions if properly taken into account in policy design and implementation. ${ }^{23}$

The OECD report concluded also that offering regional authorities a stronger role could be very useful in enabling Korea to address key challenges associated with the aging population, building stronger social cohesion in the face of current income inequality, and moving to a low carbon economy. ${ }^{24}$

A recent OECD study of innovation has offered interesting insights into regional development in China. ${ }^{25}$ China is a highly decentralised country in spending on education, health and social welfare. However, science and technology investment has been relatively centralised, with over 60 per cent of expenditure in this field being contributed centrally, notwithstanding a steady increase in the expenditure of sub-national governments on science and technology as a proportion of government expenditure over the period 1995-

\footnotetext{
${ }^{21}$ OECD, Industrial Policy and Territorial Development: Lessons from Korea Development Studies Centre. Paris, OECD Publishing, 2012, p. 87.

22 Ibid.

23 OECD, Industrial Policy and Territorial Development: Lessons from Korea Development Studies Centre. Paris, OECD Publishing, 2012, p. 139. See also Lee, Y-S. 'Balanced Development in Globalizing Regional Development? Unpacking the New Regional Policy of South Korea' Regional Studies ,Vol. 43 No. 3, 2009.

24 OECD, Industrial Policy and Territorial Development: Lessons from Korea Development Studies Centre. Paris, OECD Publishing, 2012 p. 145.

25 OECD, China Reviews of Innovation Policy, Paris, 2008.
} 
2005. Horizontal links are visibly stronger amongst agencies at the provincial level than they are nationally, thus increasing their flexibility.

The OECD review includes case studies of three different regions, as a means of assessing the contribution that might be made through regional innovation systems. The studies raise issues about the problems some regions have in targeting resources tightly enough at the parts of the innovation system where they are needed most. Secondly, performance targets were developed and monitored nationally, without any sensitivity to regional variations in circumstances, and had suffered from a focus on the indicators rather than the underlying intent. A third question in the review was whether there was an appropriate balance between national and regional government influence over the direction of the plans, while a fourth suggested that provincial-level plans did not recognise variations in regional development within a particular province.

Beyond the examples of national policy, the potential value of supranational, cross-border regional initiatives has been recognised in at least one key region in Asia. The Greater Mekong Subregion Program was established twenty years ago by Cambodia, Thailand, Vietnam, Laos, Myanmar and the Yunnan Province of China. The Chinese Autonomous Region of Guangxi Zhuang joined in 2004. The Asian Development Bank (ADB) has acted as the Secretariat of the Program. By December 2009, more than US $\$ 11$ billion had been invested in 44 projects mostly related to infrastructure and communicable disease control. ${ }^{26}$

The GMSEP has delivered many of these projects in a manner which has contributed to the economic foundations for the region, and simultaneously contributed to reduced poverty. As in Europe, the 'crossborder' character of these initiatives has been identified as a key element of their success:

The case for economic cooperation among countries with shared borders has long been recognized as contributing to create larger markets for national producers and consumers and to allow for scale economies by reducing barriers to trade, capital and labour. Regional cooperation is particularly relevant for land-locked countries, enabling them to integrate with external markets. Crossborder cooperation facilitates the development of regional infrastructure networks and management of spillover of costs and benefits across borders. ${ }^{27}$

While progress has been made on significant infrastructure projects, the political negotiations to maximise the economic and social value of the new resources continues to take time, the potential for increased cross border movement of people, goods and services is yet to be realised.

This review is only a beginning, but it illustrates the range of interest in regional development in the Asian region. It encompasses activity in local

${ }^{26}$ GMSECP, Greater Mekong Subregion Economic Cooperation Program, Strategic Framework 2012-22: Background Paper, 2010.

27 Ibid, p.1. 
politics, regional economic development, infrastructure development, crossborder collaboration, and key support from regional supranational institutions such as the ADB. On the surface, this does not seem dissimilar to the picture in Australia or even Europe. A closer look, however, suggests that the scale and coherence of policy across the Asian geographic space is fundamentally different from that in Europe.

\section{Possible Implications of EU Regional Policy for Asia}

To consider how Asian integration might benefit at all from consideration of the EU mode of regionalism, it might be useful in the first instance to summarise some of the key elements of how Regional Policy has contributed to the EU model of integration. These elements of policy formation would be useful also in Australia.

Key features of the EU Regional Policy model include:

- a coherent vision for the economic, social and environmental future of the city-regions and other spatial areas which make up the supranational region;

- a willingness of wealthier nations to contribute directly to enhancing the well-being of other nations in their region, albeit with a strong element of self-interest;

- the value of international incentives in building the Single Market;

- the importance of openness to negotiation and dialogue about both key concepts and implementation, as very difficult tensions can be resolved over time;

- the importance of sensitivity to multilevel governance, encompassing not only the EU and Member States, but also regional authorities themselves, cross-border authorities, and major regional institutions such as supranational regional investment houses;

- the importance of effective coordination of different authorities in the same geographic space;

- the significance of a comprehensive approach to regional development policies, linking economic, social and environmental concerns so that the outcomes in one domain support those of another; and

- some benefits to the development of some regions.

There has been a great deal of debate about the European model of integration and its relevance to other parts of the world. ${ }^{28}$ Much of this work has focused on the international relations and economics aspects of the integration process and an institutional approach, rather than the prospects of social cohesion, including the broader objectives of EU regional policy. However, in reviewing the implications of the European model for Latin America, Tugores pays specific attention to the implications of 'cohesion' policy, noting the complexities involved. Tugores carefully considers differences between Europe and Latin America, noting the much greater inequality and poverty of

${ }^{28}$ See T. Christiansen, E. Kirchner and P. Murray, (eds.) The Palgrave Handbook of EU-Asia Relations, Palgrave, Basingstoke, 2013. 
the latter region, as well as their different places in global production networks. Another major consideration is the scope of integration which is sought in Latin America, compared with Europe, an issue which is pertinent particularly to the integration processes in Asia. He concludes: if a commitment is made to a deeper process, however, the challenge of cohesion appears more clearly as a "shared concern"; it is seen as complementary, not accessorial or counterposed, to the challenge of efficiency and/or growth... in Europe, this option required a long maturation process with inherent difficulties... [However,] it provides a perspective on how to take advantage of the integration process itself, even in its initial phases, in order to generate a framework of reform and modernization of productive, institutional structures that propitiate modernization, not only economic and entrepreneurial, but also social and political, a modernization capable of galvanizing human potential, dynamism and progress. ${ }^{29}$

Notwithstanding that the Asian integration process is markedly different from the scope and intent of the European Union, there are striking parallels as Asian integration remains committed to the development of a single market, and to enhanced political-security and socio-cultural cooperation. Taken together, these suggest that according to Tugores's observations, Asian political leaders and policy developers may wish to consider whether they have shared interests in the development of one another's subnational regions. However, the absence of institutional arrangements to support the intense negotiation and process of resource allocation which has characterised EU Regional Policy make it difficult to see how the redistributive processes could be managed effectively, efficiently and transparently, other than on a region by region basis, as with the Greater Mekong.

Nevertheless, the points raised about comprehensive horizontal and vertical coordination of development policies, encompassing social cohesion as well as economic issues, have clear relevance to most parts of the world, including Asian countries. Furthermore, the relevance of subnational regions to the wider objectives of a single market might mean that at some point, the wealthier nations might see that their interests and those of the region could be enhanced by some contribution to the development of geographic areas within other nations on either a bilateral or multilateral basis. At that point, the institutions and experience of the EU with multilevel governance might well be useful models to consider, for better and worse. For the EU, the economic agenda has provided impetus, but the wider implications encompass greater cohesion and capacity-building. As Tugores noted, this prompts a much broader process for 'galvanizing human potential'.

\footnotetext{
${ }^{29}$ Tugores, op.cit., p.57.
} 